\title{
First evidence of light-induced spin transition in molybdenum(Iv) $\dagger$
}

\author{
N. Bridonneau, ${ }^{a}$ J. Long, ${ }^{a}$ J.-L. Cantin, ${ }^{b}$ J. von Bardeleben, ${ }^{b}$ S. Pillet, ${ }^{c}$ E.-E. Bendeif, ${ }^{c}$ \\ D. Aravena, ${ }^{d}$ E. Ruiz ${ }^{d}$ and V. Marvaud*a
}

\begin{abstract}
Photo-induced spin transition in a molybdenum-zinc complex has been evidenced and fully characterized by Squid magnetometry and several spectroscopies performed under irradiation (IR, EPR, etc.). The phenomenon has been confirmed by X-ray diffraction and DFT calculations yielding a Light-Induced Excited Spin State Trapping Effect (LIESST) on a $4 \mathrm{~d}$ transition metal ion.
\end{abstract}

Light is an attractive external trigger for the control of spin transition. ${ }^{1}$ The relative LIESST effect (Light Induced Excited Spin State Trapping), firstly demonstrated by Hauser et al., usually concerns octahedral complexes with a central transition metal ion having $\mathrm{d}^{4}-\mathrm{d}^{7}$ electronic configuration. ${ }^{2}$ Most of the examples concern iron compounds that show reversible bistability between Low Spin (LS) and High Spin (HS) states, when subjected to external perturbation such as light irradiation with an appropriate wavelength (d-d or metal-ligand charge transfer). The optical spin transition usually takes place at low temperature from the ${ }^{1} \mathrm{~A}_{1}$ low spin state to the ${ }^{5} \mathrm{~T}_{2}$ high spin state. ${ }^{3}$ The relaxation process, back to the LS ground state, can be followed by spectroscopic methods as a function of temperature $\left(T_{\text {LIESST }}\right.$ is usually below $80 \mathrm{~K}$; it might be above $132 \mathrm{~K}$ for the highest relaxation temperature investigated so far). ${ }^{4}$ Concerning other metallic ions, light induced spin transition in nickel species has been evidenced in a square-planar complex Ni(II)-tetrakis(pentafluorophenyl)porphyrin (low spin and diamagnetic) connected to a 3-azopyridine ligand, which can be switched between cis and trans configurations. When the azopyridine ligand is in the

\footnotetext{
${ }^{a}$ IPCM-CNRS-UMR-8232, UPMC-Univ. Paris 6, cc 42, 4 place Jussieu, 75252 Paris Cedex 05, France. E-mail: valerie.marvaud@upmc.fr; Fax: +33 (0)1 442738 41; Tel: +33 (0)1 44273277

${ }^{b}$ INSP - CNRS UMR-7588, UPMC-Univ. Paris 6, 4 place Jussieu, 75252 Paris Cedex 05, France

${ }^{C}$ CRM2, UMR CNRS 7036, Institut Jean Barriol, Université de Lorraine, 54506 Vandoeuvre-les-Nancy, France

${ }^{d}$ Departament de Química Inorgànica and Institut de Recerca de Química Teòrica $i$ Computacional, Universitat de Barcelona, Diagonal 645, E-08028 Barcelona, Spain

$\dagger$ Electronic supplementary information (ESI) available. CCDC 1009240 (1). For ESI and crystallographic data in CIF or other electronic format see DOI: 10.1039/ c5cc01714a
}

trans configuration, it binds well to the axial position of the square-planar nickel-porphyrin complex, switching to an octahedral geometry with a high spin, paramagnetic state $(S=1) .^{5}$

For other elements, and especially for $4 \mathrm{~d}$ transition metal ions, spin transition in molybdenum(rv) has been suggested in the context of photoswitchable MoCu complexes, ${ }^{6}$ by X-ray magnetic circular dichroism experiments, using a highly energetic synchrotron X-ray beam as a source of irradiation. But this effect has only been demonstrated in MoCu complexes, with potential correlation to photo-induced electron transfer.

In order to better understand the origin of the photomagnetic behaviour of molybdenum-copper complexes, ${ }^{7}$ we prepared a series of trinuclear compounds, viewed as reference species, $\left[\mathrm{Mo}(\mathrm{CN})_{8} \mathrm{Zn}_{(2-x)} \mathrm{Cu}_{x}\{\text { tren }\}_{2}\right]$ with $(x=0,0.05,0.1,0.2$; tren $=$ tris(2-aminoethylamine)), denoted as $\mathrm{MoZn}_{2}$ and $\mathrm{MoZn}_{(2-x)} \mathrm{Cu}_{(x)}$ respectively. The mixed species, $\operatorname{MoZn}_{(2-x)} \mathrm{Cu}_{(x)}$ complexes, entirely analysed elsewhere, ${ }^{8}$ clearly indicate that, in addition to spin transition, the photo-induced charge transfer mechanism $\mathrm{Mo}(\mathrm{IV}) \mathrm{Cu}(\mathrm{II}) \rightarrow \mathrm{Mo}(\mathrm{v}) \mathrm{Cu}(\mathrm{I})$ subsists and is not completely ruled out. The compound $\mathrm{MoZn}_{2}$, fully described in the present communication, exhibits a unique photomagnetic behaviour, attributed to a spin transition from $\mathrm{Mo}(\mathrm{rv}-\mathrm{LS}), S=0$ to $\mathrm{Mo}(\mathrm{rv}-\mathrm{HS})$, $S=1$, which confirms the possible LIESST effect in a 4 d metallic ion and might explain unelucidated photomagnetic behaviours described in the literature. ${ }^{9}$

The $\mathrm{MoZn}_{2}$-tren (1) complex was obtained by slow addition of an aqueous solution of $\mathrm{K}_{4}\left[\mathrm{Mo}^{\mathrm{IV}}(\mathrm{CN})_{8}\right] \cdot 2 \mathrm{H}_{2} \mathrm{O}$ in a water-acetonitrile mixture of $\mathrm{Zn}(\mathrm{OAc})_{2} \cdot 2 \mathrm{H}_{2} \mathrm{O}$ and the tren ligand. An excess of the zinc complex was required in order to avoid immediate precipitation of the neutral species. Large yellow crystals $(0.6 \mathrm{~cm} \mathrm{long})$ were obtained after two weeks of slow evaporation of the mother liquor. Complex 1 crystallizes in an orthorhombic system with the $P c a 2_{1}$ space group; cell parameters are $a=14.7778(3) \AA, b=14.8566(3) \AA$ and $c=31.0576(7) \AA$ with a cell volume of $V=6818.6(2) \AA^{3}$. Two crystallographically independent trinuclear molecules compose the asymmetric unit. Each assembly is formed by one molybdenum center linked to two zinc fragments through cyanide bridges (Fig. 1 and Table S1, ESI $\dagger$ ). 


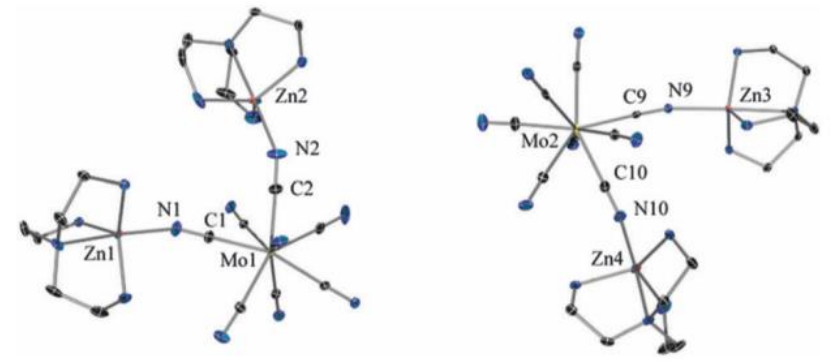

Fig. 1 X-ray structure of compound $\mathrm{MoZn}_{2}-$ tren (1): asymmetric unit (ellipsoid set to $50 \%$ ), hydrogen atoms have been omitted for clarity.

Continuous shape measurements show that the two octacyanomolybdate complexes have different geometries: ${ }^{10,11}$ one of them (Mo1) being pure based square antiprism (BSAP-8), the other (Mo2) adopting a distorted coordination environment between the dodecahedron (DD) and BSAP-8 (Table 1). Mo-C distances are slightly longer for $\mathrm{Mo} 2$, while $\mathrm{C} \equiv \mathrm{N}$ distances are similar from one molybdenum center to the other, the six free cyanide ligands being slightly longer than the bonded ones. The bridging cyanide angles are linear on the molybdenum side $\left(175.6(3)^{\circ}-178.5(3)^{\circ}\right)$, but very bent on the zinc complex side. Four very different cyanide angles are thus reported, from $137.1(3)^{\circ}$ for $\mathrm{Zn} 4-\mathrm{N} 10 \equiv \mathrm{C} 10$ to $165.0(3)^{\circ}$ for Zn3-C9 $\equiv \mathrm{N} 9$. The four zinc complexes adopt the same triangular base bipyramidal geometry with similar $\mathrm{Zn}-\mathrm{N}$ bond lengths. All complexes are well isolated from each other; the shortest intermolecular metal-metal distance reported being $6.424 \AA$.

Photomagnetic measurements were realized on single crystals and homogeneous powder obtained from ground crystals, both samples giving similar results. Before irradiation, the compound shows a purely diamagnetic behaviour (slightly negative magnetization $v s$. field curve, the $\chi T$ value close to zero) expected for $\mathrm{Zn}^{\mathrm{II}}$ $\left(3 \mathrm{~d}^{10}, S=0\right)$ and $\mathrm{Mo}^{\mathrm{IV}}\left(4 \mathrm{~d}^{2}, S=0\right)$ ions. The sample was then irradiated under a 1 kOe field for 4 hours using a $405 \mathrm{~nm}$ (blue) laser beam ( $20 \mathrm{~mW}$ power) equipped with a fiber. Irradiation was achieved at a temperature of $18 \mathrm{~K}$ in order to avoid thermalization of the sample when switching off the laser. ${ }^{12}$ A clear increase of magnetization was immediately observed upon light irradiation and saturation occurred typically after 3 to 4 hours (see Fig. S3, $\mathrm{ESI} \dagger)$. After switching off the laser, the temperature was decreased to $2 \mathrm{~K}$ to obtain the first magnetization curve, then the magnetization data were recorded on the heating mode (2-300 K) (Fig. 2).

Table 1 Continuous symmetry measurement values ${ }^{10,11}$ (S for octacoordinate models: square antiprism SAPR and dodecahedron DD) for the two molecules of the ground state (Mo1 and Mo2) and the corresponding molecules after the irradiation (Mo1' and Mo2') including as well the calculated singlet-triplet energy differences calculated at B3LYP and CASSCF(CASPT2) + RASSI levels using $\left[\mathrm{Mo}(\mathrm{CN})_{8}\right]^{4-}$ fragments

\begin{tabular}{llllll}
\hline & & & \multicolumn{3}{l}{$E_{\mathrm{S} \rightarrow \mathrm{T}}\left(\mathrm{cm}^{-1}\right)$} \\
\cline { 4 - 6 } & $S($ SAPR $)$ & $S(\mathrm{TDD})$ & B3LYP & CASSCF & CASPT2 \\
\hline Mo1 & 0.196 & 2.535 & 22147 & 18898 & 24103 \\
Mo2 & 0.455 & 1.681 & 21888 & 18130 & 24313 \\
Mo1 $^{\prime}$ & 0.243 & 2.467 & 22277 & 19027 & 23777 \\
Mo2' $^{\prime}$ & 1.048 & 1.732 & 13634 & 8786 & 14681
\end{tabular}

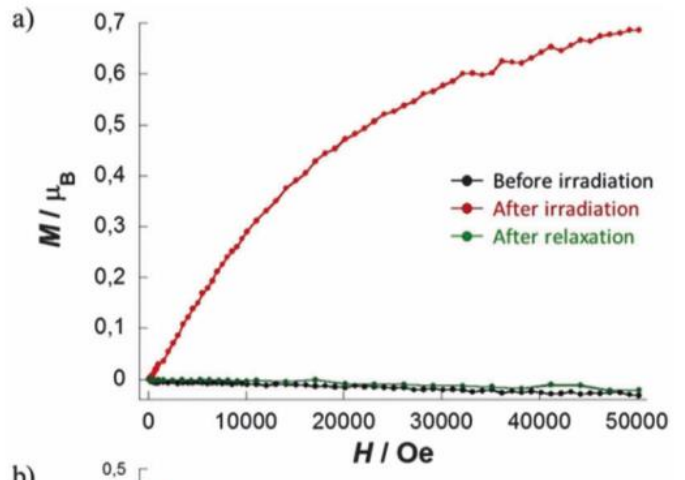

b)

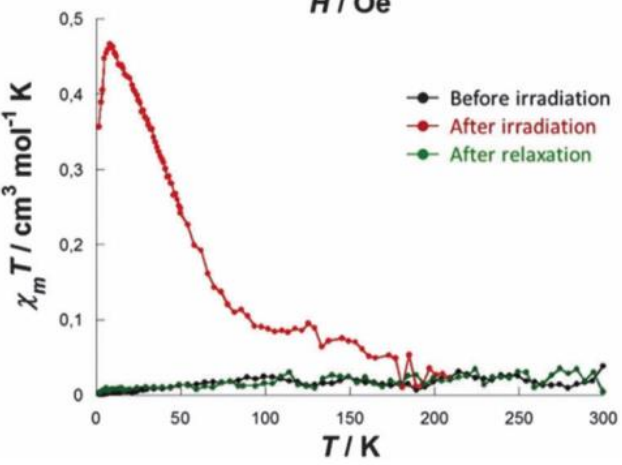

Fig. 2 Evolution of the magnetic data upon light irradiation: (a) first magnetization curve at $2 \mathrm{~K}$. (b) Temperature dependence of $\chi T$ under a $1 \mathrm{kOe}$ DC field.

Magnetic susceptibility data, recorded after irradiation, showed a drastic change in the magnetic properties: $\chi T$ reached a maximum value of $0.47 \mathrm{~cm}^{3} \mathrm{~mol}^{-1} \mathrm{~K}$ at $8.5 \mathrm{~K}$ (Fig. 2b). No evolution of the magnetic susceptibility was detected after a 2 hour period of time, thus demonstrating the stability of the photoinduced state (see ESI, $\uparrow$ Fig. S4). Relaxation of the process occurred gradually when heating the compound (at about $90 \mathrm{~K}$ ) and both curves merge at around $180 \mathrm{~K}$. Important evolution of the magnetization curve was also recorded after irradiation (Fig. 2a), indicating clearly the presence of spin carriers. Saturation of the magnetization was obtained at $50 \mathrm{kOe}$ with a value of $0.69 \mu_{\mathrm{B}}$. Comparison of this curve with a simulated Brillouin function considering an $S=1$ species $(g=2.1)$ allowed extracting a transformation rate of about $50 \%$ of the compound. Note that this rate is in very good accordance with the experimental $\chi T$ value being close to the theoretical one of $0.50 \mathrm{~cm}^{3} \mathrm{~mol}^{-1} \mathrm{~K}$ expected for an $S=1$ moiety $(50 \%)$. The sample was then heated to room temperature for at least two hours to obtain a full relaxation of the system. New magnetization $v$ s. field data showed that the compound achieved a complete relaxation (Fig. 2a) and that the effect is fully reversible.

In order to highlight potential crystal modifications upon light irradiation, 1 was introduced into an EPR glass holder and rapidly frozen to $4 \mathrm{~K}$, then irradiated as previously described. The crystal showed no apparent modification of the shape and size due to light irradiation, but a bright red colour was observed instead of the initial yellow one (Fig. 3), reflecting the photochromic properties of the compound. After approximatively two minutes, the crystal recovered its original colour as its temperature increased. A thermochromic effect has not been detected in 


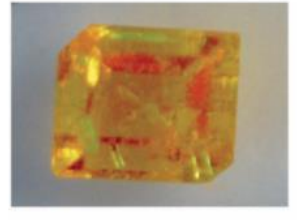

$\mathrm{Mo}^{\mathrm{IV}}{ }_{\mathrm{LS}} \mathrm{Zn}_{2}{ }_{2}$-tren

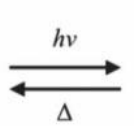

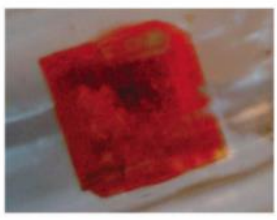

$\mathrm{Mo}^{\mathrm{IV}}{ }_{\mathrm{HS}} \mathrm{Zn}_{2}$-tren
Fig. 3 Colour change of a MoZn $n_{2}$-tren crystal upon light irradiation.

the range of $300-400 \mathrm{~K}$, probably due to partial dehydration of the compound.

The photo-magnetic behaviour of $\mathbf{1}$ has also been investigated by several additional techniques: EPR spectroscopy, XMCD experiments, IR and single crystal XRD. These experiments are fully detailed in the ESI. $\dagger$

Investigation by single crystal X-ray diffraction, at low temperature, under irradiation, indicates clearly a modification of the cell parameters, as well as a progressive amorphization of the crystal, which prevents a crystallographic analysis to be performed at completion of the photo-transformation. A structural analysis after $30 \mathrm{~min}$ illumination at $10 \mathrm{~K}$ (laser beam $405 \mathrm{~nm}$, $P=70 \mathrm{~mW}$ ), which corresponds to a very incomplete phototransformation with a yet limited amorphization progress, has been undertaken. The corresponding derived crystal structure is less accurate than the ground state crystal structure, but nevertheless sufficiently good to allow the trend of some structural reorganization to be derived. 76836 reflections were measured up to a maximum resolution of $\theta_{\max }=31.51^{\circ}$ and merged to 21900 unique reflections $\left(R_{\text {int }}=0.0759\right)$. The new parameters are

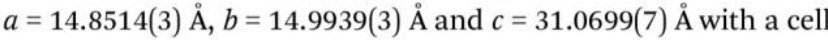
volume of $V=6918.6(3) \AA^{3}$. The analysis indicates modifications localized only on one molecule (Mo2) with an elongation of the Mo-Zn4 distance (Fig. 4). Due to the amorphization process, crystallographic analysis cannot be performed further.

If we compare the molecular structure of the ground state to the photo-irradiated state (corresponding to the average structure), we can draw the same conclusion. For the first molecule (Fig. 4, left), no significant structural distortion may be detected, while for the second molecule (Fig. 4, right), a displacement of the $\mathrm{Zn} 4$ atom with respect to the Mo2 centre is evident.

Electronic structure calculations have been carried out to analyze the energetics of the excited states for the coordination of the molybdenum centers (see Computational Details in the
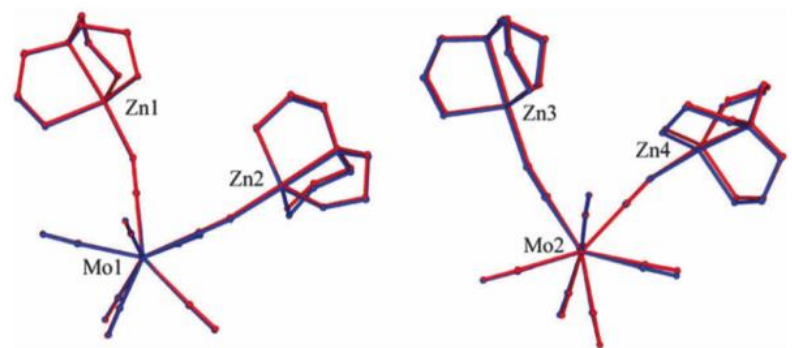

Fig. 4 Superposition of the structural models of the ground state (in blue) and an average photo-irradiated state (in red) of 1 .
Experimental Section); CASSCF/CASPT2 and DFT calculations were performed on the $\left[\mathrm{Mo}(\mathrm{CN})_{8}\right]^{4-}$ fragments (Table 1). Both methods clearly show that the photo-induced Mo2' coordination gives a relatively lower singlet-triplet excitation energy.

The Mo1 and photo-induced Mo1' centers have approximately the same geometry showing that such centers remain almost unchanged after the irradiation while significant structural changes and also changes in the electronic structure are detected between the Mo2 and Mo2' centers. This fact is in agreement with a transformation rate of around $50 \%$ because only one of the two molecules has the appropriate structure to undergo spin transition.

The analysis of the coordination mode of the Mo2 centers shows that the complexation of molybdenum with $[\mathrm{Zn}(\operatorname{tren})]^{2+}$ complexes enabled us to get an intermediate geometry of the Mo2' coordination polyhedron. But the main changes in the coordination sphere between $\mathrm{Mo} 2$ and $\mathrm{Mo}^{2}$ centers are an elongation of one of the Mo-C bond distances ( $0.2 \AA$ involved in a $\mathrm{Mo}-\mathrm{C}-\mathrm{N}-\mathrm{Zn}$ bond sequence) and the corresponding $\mathrm{C}-\mathrm{N}-\mathrm{Zn}$ angle (from $137.9^{\circ}$ in $\mathrm{Mo} 2$ to $114.8^{\circ}$ in $\mathrm{Mo2}^{\prime}$ ). The increase of the Mo-C bond distance that is almost aligned with the $y$ axis causes a stabilization of the empty $\mathrm{d}_{x^{2}-y^{2}}$ molecular orbital (for the square antiprism low-spin $S=0 \mathrm{Mo}(\mathrm{Iv})$ cation) reducing the energy difference with the doubly-occupied $\mathrm{d}_{z^{2}}$ orbital. This distortion can be responsible for reducing the energy gap between the two lowest $4 \mathrm{~d}$ orbitals and for promoting the relative stabilization of the triplet state of the Mo2' centers (Fig. 5).

Taking into account all these results, we can suggest that 1 exhibits a light induced excited spin state trapping (LIESST) effect, as already observed mainly in iron(II) complexes. The compound can be switched upon light irradiation from the low spin state $(S=0)$ to the high spin state $(S=1)$, leading to drastic changes in the magnetic properties. Only one of the two molecules present in the unit cell is active towards spin-transition, explaining why despite all our attempts we never succeeded in reaching more than $50 \%$ of the transformation rate. As confirmed by electronic structure calculations, the specific geometry of the coordination polyhedron (distorted antiprism) might justify the stabilization of the triplet state (Fig. 5).

The results presented here show photo-induced spin transition, achievable on a molybdenum(Iv) center, evolving from $\mathrm{Mo}^{\mathrm{IV}}{ }_{\mathrm{LS}}(S=0)$ into $\mathrm{Mo}^{\mathrm{IV}}{ }_{\mathrm{HS}}(S=1)$. This study puts forward that such a phenomenon could be induced on a $4 \mathrm{~d}$ transition metal ion, as already suggested in the literature. Work is in progress to analyse the photophysical process of the LIESST effect and specifically the relaxation process by spectroscopic methods as a function of temperature. The observed phenomenon is

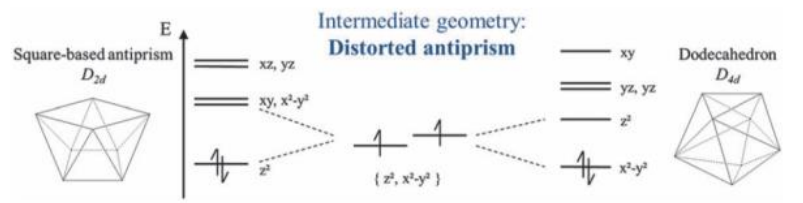

Fig. 5 The intermediate geometry of molybdenum Mo2' centers could stabilize the triplet state of the Mo ${ }^{\text {IV }}$ system. 
explained by a specific coordination environment of molybdenum and offers an additional point of view on photo-magnetism based on octacyanomolybdate compounds. It demonstrates as well that a spin crossover phenomenon might occur in a new class of coordination compounds. The switching properties make such materials potential candidates for practical applications in sensors as well as optical devices.

The research has been supported by the CNRS - UMR 8232, UPMC, Labex Michem, the French Ministry of Research, ANR Switch (2010-Blan-712) and ANR E-storic (14-CE05-0002), Spanish Ministerio de Economía y Competitividad (CTQ2011-23862-C02-01) and the regional Generalitat de Catalunya authority (2009SGR1459). The authors thank Marie-Anne Arrio, Laurent Lisnard and Katharina Ollefs for XMCD experiments.

\section{Notes and references}

1 (a) P. Gütlich, A. B. Gaspar and Y. Garcia, Beilstein J. Org. Chem., 2013, 9, 342; (b) M. A. Halcrow, Coord. Chem. Rev., 2009, 253, 2493; (c) J. Olguín and S. Brooker, Coord. Chem. Rev., 2011, 255, 203; (d) S. Hayami, Y. Komatsu, T. Shimizu, H. Kamihata and Y. H. Lee, Coord. Chem. Rev., 2011, 255, 1981; (e) J. Tao, H. Maruyama and O. Sato, J. Am. Chem. Soc., 2006, 128(6), 1790.

2 (a) S. Decurtins, P. Gutlich, C. P. Kohler, H. Spiering and A. Hauser, Chem. Phys. Lett., 1984, 105, 1; (b) P. Gütlich and A. Hauser, Coord. Chem. Rev., 1990, 97, 1; (c) P. Gutlich, A. Hauser and H. Spiering, Angew. Chem., Int. Ed., 1994, 106, 2109; (d) A. Hauser, Chem. Phys. Lett., 1983, 124, 543; (e) P. Gutlich, A. Hauser and H. Spiering, Angew. Chem., Int. Ed., 1994, 33, 2024.
3 P. Gütlich and A. Hauser, Coord. Chem. Rev., 1990, 97, 1.

4 (a) S. Hayami, Z.-Z. Gu, Y. Einaga, Y. Kobayashi, Y. Ishikawa, Y. Yamada, A. Fujishima and O. Sato, Inorg. Chem., 2001, 40, 3240; (b) J.-F. Létard, J. Mater. Chem., 2006, 16, 2550.

5 S. Thies, H. Sell, C. Schütt, C. Bornholdt, C. Näther, F. Tuczek and R. Herges, J. Am. Chem. Soc., 2011, 133, 16243.

6 (a) M.-A. Arrio, J. Long, C. Cartier dit Moulin, A. Bachschmidt, V. Marvaud, A. Rogalev, C. Mathoniere, F. Wilhelm and P. Sainctavit, J. Phys. Chem. C, 2010, 114, 593; (b) S. Brossard, F. Volatron, L. Lisnard, M.-A. Arrio, L. Catala, C. Mathoniere, T. Mallah, C. Cartier dit Moulin, A. Rogalev, A. Smekhova and P. Sainctavit, J. Am. Chem. Soc., 2012, 134, 222.

7 (a) T. Hozumi, K. Hashimoto and S.-I. Ohkoshi, J. Am. Chem. Soc., 2005, 127, 3864; (b) Y. Arimoto, S.-I. Ohkoshi, Z. J. Zhong, H. Seino, Y. Mizobe and K. Hashimoto, J. Am. Chem. Soc., 2003, 125, 9240; (c) G. Rombaut, M. Verelst, S. Golhen, L. Ouahab, C. Mathoniere and O. Kahn, Inorg. Chem., 2001, 40, 1151; (d) A. Bleuzen, V. Marvaud, C. Mathoniere, B. Sieklucka and M. Verdaguer, Inorg. Chem., 2009, 48, 3453; (e) J. M. Herrera, V. Marvaud, M. Verdaguer, J. Marrot, M. Kalisz and C. Mathoniere, Angew. Chem., Int. Ed., 2004, 43, 5468.

8 N. Bridonneau, PhD thesis, UPMC, Paris 6, France, 2013.

9 (a) C. Mathoniere, R. Podgajny, P. Guionneau, C. Labrugere and B. Sieklucka, Chem. Mater., 2005, 17, 442; (b) T. Korzeniak, C. Mathonière, A. Kaiba, P. Guionneau, M. Koziel and B. Sieklucka, Inorg. Chim. Acta, 2008, 361, 3500-3504.

10 (a) S. Alvarez, P. Alemany, D. Casanova, J. Cirera, M. Llunell and D. Avnir, Coord. Chem. Rev., 2005, 249, 1693; (b) D. Casanova, J. Cirera, M. Llunell, P. Alemany, D. Avnir and S. Alvarez, J. Am. Chem. Soc., 2004, 126, 1755; (c) J. Cirera, E. Ruiz and S. Alvarez, Organometallics, 2005, 24, 1556.

11 M. Llunell, D. Casanova, J. Cirera, P. Alemany and S. Alvarez, Shape 2.0, Program for the Stereochemical Analysis of Molecular Fragments by Means of Continuous Shape Measures and Associated Tools, 2010.

12 Y. Zhang, D. Li, R. Clérac, M. Kalisz, C. Mathonière and S. M. Holmes, Angew. Chem., Int. Ed., 2010, 49, 3752. 